\title{
Evaluation of inflammatory markers and mean platelet volume as short-term outcome indicators in young adults with ischemic stroke
}

\author{
Ahmed Dahshan * (D, Asmaa M. Ebraheim, Laila A. Rashed, Mohammed A. Farrag and Ahmed T. El Ghoneimy
}

\begin{abstract}
Background: Studying outcome predictors in patients with onset of cerebral infarction in early adult life may enhance our knowledge of disease pathophysiology and prognosis.

Aim: The aim is to identify independent predictors of short-term outcome of first-ever ischemic stroke in young adults with special emphasis on inflammatory and thrombogenic markers.

Methods: We enrolled 33 patients aged 19-44 years with first-ever ischemic stroke admitted to Kasr Alainy Stroke Unit and 33 matched controls. Clinical, radiological, and laboratory (adhesion molecules, C-reactive protein, prolactin, and mean platelet volume) evaluations were carried out. Functional outcome at 7 days after stroke onset was assessed using the modified Rankin scale, and independent predictors were identified.

Results: The most frequently identified risk factor was cardiac abnormality. Patients exhibited significantly higher levels of baseline inflammatory and thrombogenic markers compared with controls. These markers were significantly correlated with the stroke severity. Logistic regression model showed that high National Institutes of Health Stroke Scale (NIHSS) score (odds ratios $[\mathrm{OR}]=0.13 ; 95 \%$ confidence interval $[\mathrm{Cl}], 0.04-0.24 ; P=0.01$ ) and large infarction size $(\mathrm{OR}=0.11 ; 95 \% \mathrm{Cl}, 0.09-0.17 ; P=0.04)$ but not the laboratory markers were independent predictors of unfavorable outcome.
\end{abstract}

Conclusion: Our data suggested that higher NIHSS scores and large infarction size served as independent predictors of short-term unfavorable outcome, while inflammatory and thrombogenic markers did not.

Keywords: Inflammatory markers, Ischemic stroke severity, Short-term outcome, Young adults

\section{Introduction}

Recently, a noticeable increase in the incidence of stroke, a common cause of disability in young adulthood, has been reported. Being the main power of any nation, studying brain ischemia in those victims is of paramount importance in order to establish strategies which might alleviate the psychological and financial burdens on the patients and communities [1]. Inflammation and thrombogenesis have fundamental role in the pathogenesis of brain ischemia. Inflammation is a process triggered by tissue injury secondary to infection, trauma, or ischemia and

\footnotetext{
* Correspondence: drdahshanneuro@kasralainy.edu.eg Department of Neurology, Cairo University, Cairo, Egypt
}

orchestrated by leukocytes and several molecules belonging to different families of mediators, such as cytokines, chemokines, and adhesion molecules in an attempt to restore tissue homeostasis [2]. Prolactin (PRL), the anterior pituitary hormone, is produced by many immune system cells [3] and acts as cytokine that influences proliferation, regulation, and communication of inflammatory cells [4]. Moreover, it is a co-factor of platelet activation [5] which is a crucial mechanism in arterial thrombogenesis. Mean platelet volume is an indicator of platelet activation [6]. As a result of these dynamic processes that take place in the brain during ischemic injury, several molecules are released into the peripheral blood. Studying these molecules as biomarkers of these processes and their influence on 
functional outcome is an area of active investigation [7]. Thus, the current study was conducted to identify independent predictors of short-term outcome of first-ever ischemic stroke in young adults with special emphasis on inflammatory and thrombogenic markers. Exploration of this area might substantially lead to better understanding of the pathophysiology of the disease and emergence of new therapeutic strategies, improving both morbidity and survival.

\section{Subjects and methods Study population}

This is a prospective, single-center, case-control study. The enrolled patients $(n=33)$ were admitted to the Stroke Unit of Kasr Alainy Hospital, Cairo University, Egypt, during a period extending from October 2016 to December 2017. All patients were admitted within $24 \mathrm{~h}$ of experiencing their first-ever acute ischemic strokes (AIS). The diagnosis was based on both clinical assessment and cerebral imaging according to the most recent definition of stroke for clinical trials. It requires either focal neurological deficit lasting $>24 \mathrm{~h}$ or imaging of an acute clinically relevant brain lesion in patients with rapidly vanishing symptoms [8]. The inclusion criteria were age range between 18 and 45 years and any sex. The exclusion criteria were pregnancy for females, venous sinus thrombosis, intracerebral hemorrhage, transient ischemic attack (TIA), seizure at onset of the event, malignant tumor, a history of recent surgery or trauma during the preceding 3 months, renal insufficiency (creatinine > $2 \mathrm{mg} / \mathrm{dl}$ ), febrile disorders, congestive heart failure, acute myocardial infarction or acute coronary event within the last 3 months, peripheral vascular disease, carotid atherosclerosis (IMT $>0.9 \mathrm{~cm}$ ) ( as mentioned by Touboul and colleagues, in Cerebrovascular Disease, Basel, Switzerland), liver dysfunction and ongoing treatment with neuroleptics, lithium, hormonal therapy, or the use of illicit drugs. Control group included 33 age- and sexmatched healthy individuals without clinical evidence of peripheral, cardiac, or cerebral ischemic events. Informed consent was obtained from the participants or their relatives, and the ethical committee of Neurology Department, Cairo University, approved the study.

\section{Clinical evaluation}

Clinical data were collected. Demographics (age and sex), history of risk factors, comorbidities (hypertension, diabetes mellitus, hyperuricemia, dyslipidemia, previous TIA, smoking, cardiac troubles, etc.), and time-lapes between the event and admission were obtained. Prestroke and post- stroke medications including oral anticoagulants, antiplatelet agents, antihypertensive drugs, antidiabetic drugs, statins, and IV thrombolysis were recorded.
After general medical and neurological examination, assessment of stroke severity using National Institutes of Health Stroke Scale (NIHSS) was carried out. Moreover, electrocardiogram was performed to capture any cardiac rhythm abnormality or abnormal wave morphology. Strokes were classified according to the criteria of the TOAST (Trial of Org 10172 in Acute Stroke Treatment) classification [9].

\section{Radiological evaluation}

Brain computed tomography (CT) was carried out on admission for all studied patients to confirm the presence of cerebral infarction and to exclude hemorrhage or old ischemic events. Patients underwent MRI subsequently to properly assess the site and size of the infarction using a 1.5 Tesla Phillips Intera ${ }^{\circ}$ scanner (Phillips Corporation, Netherland, 2003). The site of infarction was determined according to the vascular territory, and the size of infarction was determined by the largest diameter of the lesion [10].

Carotid and vertebrobasilar duplex and Doppler studies were performed to assess the intima media thickness (IMT) at the distal far wall of the common carotid artery and exclude the presence of atherosclerosis or arterial dissection.

Transthoracic echocardiography was performed to assess the chamber dimensions, valve state, ejection fraction, and regional wall motion.

\section{Laboratory evaluation}

Fasting blood glucose, $2 \mathrm{~h}$ post-prandial blood glucose, complete blood count (CBC), erythrocyte sedimentation rate (ESR), kidney and liver functions, electrolytes, lipid profile, uric acid, and international normalized ratio (INR) were measured using routine laboratory methods. Collagen profile was scheduled in clinically suspected patients, but results were not available by the time of assessment "during the first week after acute event."

Furthermore, MPV, soluble serum cell adhesion molecules (E-selectin, VCAM-1), high sensitivity C-reactive protein (hs-CRP), and PRL were tested. All blood samples were collected on the first day of admission before initiation of any drug therapy. Venous blood was collected and centrifuged, and serum samples were kept at $-20^{\circ} \mathrm{C}$ until assay. Measurement of MPV was performed using automated HESKA CBC-Diff hematological analyzer (HESKA Corporation, USA, 2002). Assessment of serum levels of the other markers was performed using the ELISA technique. Laboratory test specifications are listed in Table 1.

\section{Follow-up}

On the seventh day, functional outcome was evaluated according to the modified Rankin scale (mRS) score 
Table 1 Laboratory test specifications

\begin{tabular}{|c|c|c|c|c|}
\hline Test & Method & Detection range & Sensitivity & Specificity \\
\hline Human E-selectin ELISA Kit (USA, 2015) & ELISA & $0.312-100 \mathrm{ng} / \mathrm{ml}$ & $0.078 \mathrm{ng} / \mathrm{ml}$ & $95 \%$ \\
\hline Human vascular cell adhesion molecule 1 (VCAM-1) ELISA Kit (USA, 2015) & ELISA & $1.563-100 \mathrm{ng} / \mathrm{ml}$ & $0.61 \mathrm{ng} / \mathrm{ml}$ & $95 \%$ \\
\hline Human Prolactin ELISA Kit (UK, 2016) & ELISA & $1.56-100 \mathrm{ng} / \mathrm{ml}$ & $0.94 \mathrm{ng} / \mathrm{ml}$ & $98 \%$ \\
\hline C-Reactive Protein High Sensitivity ELISA Kit (UK, 2017) & ELISA & $0-0.1 \mathrm{mg} / \mathrm{ml}$ & $0.01 \mathrm{mg} / \mathrm{ml}$ & $96 \%$ \\
\hline
\end{tabular}

ELISA enzyme-linked immunosorbent assay

blinded to the laboratory results. After obtaining the scores, the patients were classified into two groups, with good (mRS, 0-2) and with poor (mRS, 3-6) outcomes according to Zeng and colleagues [11]. Laboratory markers were also reevaluated.

\section{Statistical analysis}

Results were tabulated and statistically analyzed by using personal Acer windows computer and statistical package SPSS version 17 (USA, 2003). Data were statistically described in terms of median, range; mean \pm standard deviation (SD); frequencies (number of cases); and relative frequencies (percentages) when appropriate. Sample was tested for normality using the Kolmogorov-Smirnov test. Unpaired Student's $t$ test was used for comparison between two groups of quantitative variables. Paired $t$ test was used to compare the patients' results initially and after reevaluation. The Mann-Whitney test was used for comparison between two groups of categorical data or frequency of events. Pearson and Spearman's correlation coefficient $(r)$ was used when appropriate to correlate between laboratory sample measurements, clinical variables, and radiological findings. The strength of correlation was interpreted as follows: $1=$ perfect correlation, $>0.70=$ strong correlation, $>$ $0.50=$ moderate correlation, $>0.30=$ weak correlation, and $0=$ no linear correlation.

Multiple linear regression analysis was used to assess factors contributing to outcome independently. $P$ values less than 0.05 were considered as statistically-significant. $P$ values less than 0.01 were considered as highly significant.

\section{Results}

\section{Clinical and radiological characteristics of study} population

The patients presented to the Stroke Unit at Kasr Alainy Hospital within 5 to $22 \mathrm{~h}$ from the onset of the neurological deficit. Their ages ranged from 19 to 44 years with a mean of $36.4 \pm 7.4$ years. Patient group included 19 males $(57.6 \%)$ and 14 females $(42.4 \%)$. The most frequently encountered risk factors were cardiac diseases. They were variable in etiology. Six patients had rheumatic heart disease, five patients gave history of congenital heart disease, and two patients had ischemic heart disease.
Investigating the possible cause of the ischemic infarction according to TOAST classification, 13 patients (39.6\%) exhibited cardioembolism (3 of them were known AF before admission on no medications, 6 patients were discovered AF on admission, and 4 patients had normal sinus rhythm but their echocardiographs revealed valvular abnormalities). In 14 patients (42.4\%), the causes were undifferentiated. On the other hand, 3 patients (9\%) had other differentiated causes (2 patients were known to have systemic lupus erythematosus, 1 patient was known to have antiphospholipid syndrome) and 3 patients (9\%) exhibited small vessel disease.

The control group included 15 males (45.5\%) and 18 females (54.5\%). Their ages ranged from 20 to 44 years with a mean of $33.6 \pm 7.1$ years. Both patient and control groups were age $(P=0.12)$ and sex $(P=0.22)$ matched. The patients' clinical and radiological characteristics on admission are summarized in Table 2. Regarding control individuals, 10 of them were smokers; however, none of them reported any other risk factors.

Comparison between patients with short-term good outcome (defined as mRS $0-2$ ) and those with poor outcome (defined as mRS 3-6) revealed that there were significant differences between both groups regarding NIHSS score and infarction size on admission, being increased in patients with poor outcome. Age, sex, risk factors, time interval from the onset to clinical presentation, and infarction territory and side did not differ significantly between both groups (Table 3 ).

\section{Laboratory results}

Baseline serum levels of different cell adhesion molecules, hs-CRP, prolactin, and MPV were significantly higher in the patients compared with the controls (Table 4).

The results comparing the laboratory markers between the two outcome groups were analyzed, and the findings were as follows (Table 5):

- Baseline levels of the studied laboratory markers were not significantly different between the groups of good and poor outcomes.

- Poor outcome patients exhibited higher levels of VCAM-1 and E-selectin at follow-up compared with baseline levels. The $P$ values were 0.03 and 0.36 , respectively. 
Table 2 The patients' $(n=33)$ demographic and baseline clinical and radiological characteristics

\begin{tabular}{ll}
\hline The studied parameter & Value \\
\hline Prior vascular risk factors, $n$ (\%) & $3(9.1)$ \\
Hypertension & $2(6.1)$ \\
Diabetes & $13(39.4)$ \\
Cardiac disease & $12(36.4)$ \\
Smoking & $12(36.4)$ \\
Dyslipidemia & $2(6.1)$ \\
Hyperuricemia & \\
Stroke etiology, $n$ (\%) & $13(39.6)$ \\
Cardioembolic & $3(9)$ \\
Small vessel occlusive & $3(9)$ \\
Other differentiated causes & $14(42.4)$ \\
Undifferentiated & $13.5 \pm 5.6$ \\
Time interval from onset to presentation (hours), mean \pm SD & $11(3-19)$ \\
NIHSS score on admission, median (range) & \\
Infarction side, $n$ (\%) & $17(51.5)$ \\
Right & $16(48.5)$ \\
Left & \\
Infarction territory, $n$ (\%) & $1(3)$ \\
ACA & $27(81.8)$ \\
MCA & $5(15.2)$ \\
Infarction size (cm), mean \pm SD & $4.7 \pm 2.7$ \\
\hline
\end{tabular}

NIHSS National Institute of Health Stroke Scale, $A C A$ anterior cerebral artery, MCA middle cerebral artery, PCA posterior cerebral artery

- Good outcome patients showed significantly lower levels of E-selectin at follow-up compared with at admission levels $(P$ values $=0.04)$. The difference between both values regarding VCAM-1 was approaching significance $(P$ values $=0.05)$. The levels were lower at follow-up.

- At follow-up, E-selectin and VCAM-1 levels of the patients who showed improvement were significantly lower when compared to those with poor outcome ( $P$ values were 0.03 and 0.02 , respectively).

\section{Determining the significant indicators of functional outcome}

Multiple linear regression analysis was carried out to test for significant indicators of poor outcome (measured by mRS after 7 days). Age, sex, risk factors, size of infarction, side of infarction, infarction site, NIHSS, baseline cell adhesion molecules (E-selectin, VCAM-1), hs-CRP, prolactin levels, and MPV were entered in regression model. Higher NIHSS score and large infarction size on admission were significant independent indicators of unfavorable short-term outcome (Table 6).
Correlations between stroke severity (NIHSS score and infarction size) on admission and laboratory markers There was a moderate positive correlation between NIHSS score on admission and infarction size $(r=0.78$, $P<0.001$; Fig. 1). Moreover, there were significant positive correlations between baseline serum levels of Eselectin, VCAM-1, hs-CRP, Prolactin, MPV, and stroke severity on admission (NIHSS score and infarction size). The higher the inflammatory markers and MPV at presentation, the more the stroke severity (Table 7).

Correlations between stroke outcome (measured by mRS) and clinical, imaging, and laboratory findings on admission

There were moderate positive correlations between mRS after 7 days and NIHSS score and infarction size on admission. More favorable stroke outcome was associated with less INHSS score and infarction size on admission $(r=0.65, P=0.002 ; r=0.67, P<0.001$, respectively; Figs. 2 and 3 ).

Moreover, there were moderate positive correlations between mRS after 7 days and the levels of E-selectin, VCAM-1, hs-CRP, prolactin, and MPV on admission. The less the levels of the inflammatory markers and MPV at presentation, the better the outcome (Table 8).

Regarding management, none of the patients was candidate for thrombolytic therapy. They all received the standard care and therapy of acute ischemic stroke (proper hydration, control of risk factors, and antiplatelets in the form of acetyl salicylic acid $300 \mathrm{mg} /$ day and gastric protection). None of them was on anticoagulation or received therapeutic anticoagulation during the study period.

\section{Discussion}

\section{Clinical markers}

Undifferentiated causes according to TOAST classification were the most frequently detected (42.4\%) and that may be attributed to the short hospital stay and the presence of more than one suggested etiology in some patients. Similarly, the frequency of unknown cause of cerebral ischemia amongst the same age group in earlier reports was relatively high (31-62\%) [12-14]. This illustrates that the TOAST criteria may be too strict to be suitable in clinical practice amongst young adults [15]. The next in frequency was cardiac troubles which particularly dominated (about 39\%) as identified comorbidities and underlying causes in our young adult patients. This finding was similar to a study on older patients [16] and dissimilar to another study on the same age group [17]. Fusco and Harrigan [17] reported that arterial dissection was one of the commonest etiologies for stroke in young adults followed by inflammatory arteritis. Two other studies using the TOAST classification found high 
Table 3 Comparison between patients with good and poor outcomes regarding the demographic and baseline clinical and radiological characteristics

\begin{tabular}{|c|c|c|c|}
\hline Clinical data & Patients with good outcome $(n=6)$ & Patients with poor outcome $(n=27)$ & $P$ value \\
\hline Age (years), mean $\pm S D$ & $37.33 \pm 6.40$ & $36.22 \pm 7.73$ & 0.70 \\
\hline Female/male, $n$ (\%) & $3(50) / 3(50)$ & $11(40) / 16(60)$ & 0.95 \\
\hline \multicolumn{4}{|l|}{ Prior vascular risk factors, $n(\%)$} \\
\hline Hypertension & $1(16)$ & $2(7)$ & 0.47 \\
\hline Diabetes & $1(16)$ & $1(3)$ & 0.28 \\
\hline Cardiac disease & $3(50)$ & $10(37)$ & 0.53 \\
\hline Smoking & $4(66)$ & $8(29)$ & 0.56 \\
\hline Dyslipidemia & $3(50)$ & $9(33)$ & 0.49 \\
\hline Hyperuricemia & $1(16)$ & $1(3)$ & 0.82 \\
\hline Time interval from onset to presentation (hours), mean \pm SD & $13.67 \pm 6.53$ & $13.48 \pm 5.51$ & 0.92 \\
\hline NIHSS on admission, median (range) & $7(4-10)$ & $12(8-16)$ & $<0.01^{* *}$ \\
\hline \multicolumn{4}{|l|}{ Infarction territory, $n(\%)$} \\
\hline ACA & $0(0)$ & $1(3)$ & 0.13 \\
\hline MCA & $4(75)$ & $23(88)$ & \\
\hline PCA & $2(25)$ & $3(9)$ & \\
\hline \multicolumn{4}{|l|}{ Infarction side, $n$ (\%) } \\
\hline Right & $5(84)$ & $12(44)$ & 0.08 \\
\hline Left & $1(16)$ & $15(56)$ & \\
\hline Infarction size $(\mathrm{cm})$, mean $\pm \mathrm{SD}$ & $2.25 \pm 0.9$ & $5.07 \pm 1.83$ & $0.04^{*}$ \\
\hline
\end{tabular}

NIHSS National Institute of Health Stroke Scale, ACA anterior cerebral artery, MCA middle cerebral artery, PCA posterior cerebral artery

${ }^{*} P$ value $<0.05$ is significant

${ }^{*} P$ value $<0.01$ is highly significant

rates of atherosclerosis amongst young adults $[12,18]$. The previous reported frequency of cardiac embolism ranged from 7.8 to $25 \%[15,19,20]$. This discrepancy is mainly due to different inclusion criteria (for example, patients with increased carotid IMT were excluded from current study); furthermore, it seems that cardioembolic strokes in young adults occur at reduced frequencies in developed countries. Low socioeconomic standards and poor environmental conditions or ethnic factors might attribute to increased prevalence of rheumatic heart disease amongst Egyptians [21]. On the other hand, relatively similar

Table 4 Comparison between the patients on admission and the control individuals regarding laboratory data

\begin{tabular}{llll}
\hline Baseline levels & Patients $(n=33)$ & Controls $(n=33)$ & $P$ value \\
\hline E-selectin $(\mathrm{ng} / \mathrm{ml})$ & $18.23 \pm 3.96$ & $8.03 \pm 2.20$ & $<0.001^{* *}$ \\
VCAM-1 $(\mathrm{ng} / \mathrm{ml})$ & $31.89 \pm 7.73$ & $5.24 \pm 1.92$ & $<0.001^{* *}$ \\
hs-CRP $(\mathrm{mg} / \mathrm{l})$ & $4.28 \pm 2.27$ & $0.89 \pm 0.22$ & $<0.001^{* *}$ \\
Prolactin $(\mathrm{ng} / \mathrm{ml})$ & $10.90 \pm 3.36$ & $7.29 \pm 1.57$ & $0.048^{*}$ \\
MPV $(\mathrm{fl})$ & $6.90 \pm 2.45$ & $3.46 \pm 0.97$ & $0.039^{*}$
\end{tabular}

Data are presented as mean \pm SD. VCAM-1 vascular cell adhesion molecule 1, hs-CRP high sensitivity C-reactive protein, MPV mean platelet volume ${ }^{*} P$ value $<0.05$ is significant

${ }^{*} P$ value $<0.01$ is highly significant frequencies regarding the other risk factors were reported by Putaala and colleagues [19] and RuttenJacobs and colleagues [20].

Neither the demographic features nor the risk factors identified in our patients significantly influenced the short-term outcome. This was contrary to other studies on elderly patients which linked worse prognosis to increasing in age [16, 22], female gender [23], and cardiac embolism [16]. Narrow age range of the selected participants and over-representation of women in the older age might explain the differences. In line with our finding, Thijs and colleagues [24] found that risk factors were not significantly different between the elderly patients with independent outcome and dependent outcome.

In the current study, baseline higher NIHSS score was a significantly independent indicator of poor short-term outcome. In the acute phase of stroke, NIHSS was found to be one of the most important predictors of outcome $[25,26]$.

High baseline NIHSS was associated with adverse neurological outcome 24h [27], 14days [28], and 3 months [29] after stroke onset. Furthermore, it was proved to have a predictive validity of in-hospital complication [29]. 
Table 5 Comparison between patients with good outcome and poor outcome regarding the laboratory results on admission and after 7 days

\begin{tabular}{llll}
\hline Laboratory marker & Patients with good outcome $(n=6)$ & Patients with poor outcome $(n=27)$ & $P$ value \\
\hline E-selectin (on admission) & $19.03 \pm 2.85$ & $18.05 \pm 4.19$ & $19.70 \pm 3.02$ \\
E-selectin (at follow-up) & $15.21 \pm 2.41$ & 0.36 \\
$P$ value & $0.04^{*}$ & $31.73 \pm 7.17$ & $0.04^{*}$ \\
VCAM-1 (on admission) & $32.05 \pm 9.38$ & $37.07 \pm 9.18$ & 0.16 \\
VCAM-1 (at follow-up) & $26.96 \pm 9.39$ & $0.03^{*}$ \\
$P$ value & 0.05 & $3.91 \pm 2.11$ & $0.01^{*}$ \\
hs-CRP (on admission) & $5.98 \pm 2.38$ & $5.19 \pm 2.09$ \\
hs-CRP (at follow-up) & $3.60 \pm 1.11$ & 0.08 \\
$P$ value & 0.08 & $10.75 \pm 3.42$ \\
Prolactin (on admission) & $11.56 \pm 3.02$ & $10.78 \pm 2.94$ \\
Prolactin (at follow-up) & $11.23 \pm 2.96$ & 0.89 \\
$P$ value & 0.94 & $7.25 \pm 2.50$ \\
MPV (on admission) & $7.80 \pm 2.36$ & $7.11 \pm 2.33$ & 0.07 \\
MPV (at follow-up) & $7.36 \pm 2.45$ & 0.76 \\
$P$ value & 0.90 & 0.54 \\
\hline
\end{tabular}

Data are presented as mean \pm SD. VCAM-1 vascular cell adhesion molecule 1, hs-CRP high sensitivity C-reactive protein, MPV mean platelet volume

${ }^{*} P$ value $<0.05$ is significant

\section{Neuro-radiological markers}

In line with our result, infarction size was found to be positively correlated with the neurological deficit [30] and inversely related to the rehabilitation ability [31]. In contrast, Beloosesky and colleagues [32] denied this relation and concluded that large cortical infarctions as well as small lacunar infarctions involving the deeper tracts can cause profound clinical deficits. Baseline infarction size but not its site or side was significantly increased in the group of patients with poor outcome and could serve as an independent radiological marker for post-stroke short-term recovery. This was consistent with many previous reports using different radiological modalities [24, 25, 33].

\section{Laboratory markers}

The current study has the advantage of shedding light on the inflammatory activity during the early period following the first-ever AIS in young adults and its impact on the disease severity and outcome.

\section{CRP and adhesion molecule}

Human CRP is an acute phase reactant that is produced by the hepatocytes in response to tissue injury or infection. It is a sensitive indicator of inflammatory activity [34]. Cell adhesion molecules are cell-surface proteins that mediate cell-cell and cell-extracellular matrix interactions [35]. In the current study, levels of CRP and the studied cell adhesion molecules (E-selectin, VCAM-1) were significantly elevated in the stroke patients at the onset compared with age- and sex-matched controls. This result was in line with some previous studies $[7,36]$ and raises inquiries about the possibility of their use as on-admission tests to predict acute ischemic stroke in cases when other diagnostic procedures are inconclusive. Moreover, in our study, levels of these inflammatory markers were positively correlated with stroke severity (INHSS score, infarction size) at the onset. It seems plausible that these inflammatory markers are likely to play a pathophysiological role during the early response to vascular brain injury. The cascade of events is initiated by the release of pro inflammatory cytokines from

Table 6 Multiple linear regression analysis model for significant indicators of short-term outcome

\begin{tabular}{llllll}
\hline & Regression coefficient $(B)$ & Standard error of $B$ & Odd ratios & $95 \% \mathrm{Cl}$ & $P$ value \\
\hline NIHSS (on admission) & 0.06 & 0.02 & 0.13 & $0.04-0.24$ & $0.01^{*}$ \\
Infarction size $\left(\mathrm{cm}^{2}\right)$ & 0.08 & 0.04 & 0.11 & $0.09-0.17$ & $0.04^{*}$ \\
Constant & 0.76 & 1.21 & 2 & $1.80-3.33$ & 0.001 \\
\hline
\end{tabular}

NIHSS National Institute of Health Stroke Scale, $\mathrm{Cl}$ confidence interval

${ }^{*} P$ value $<0.05$ is significant 


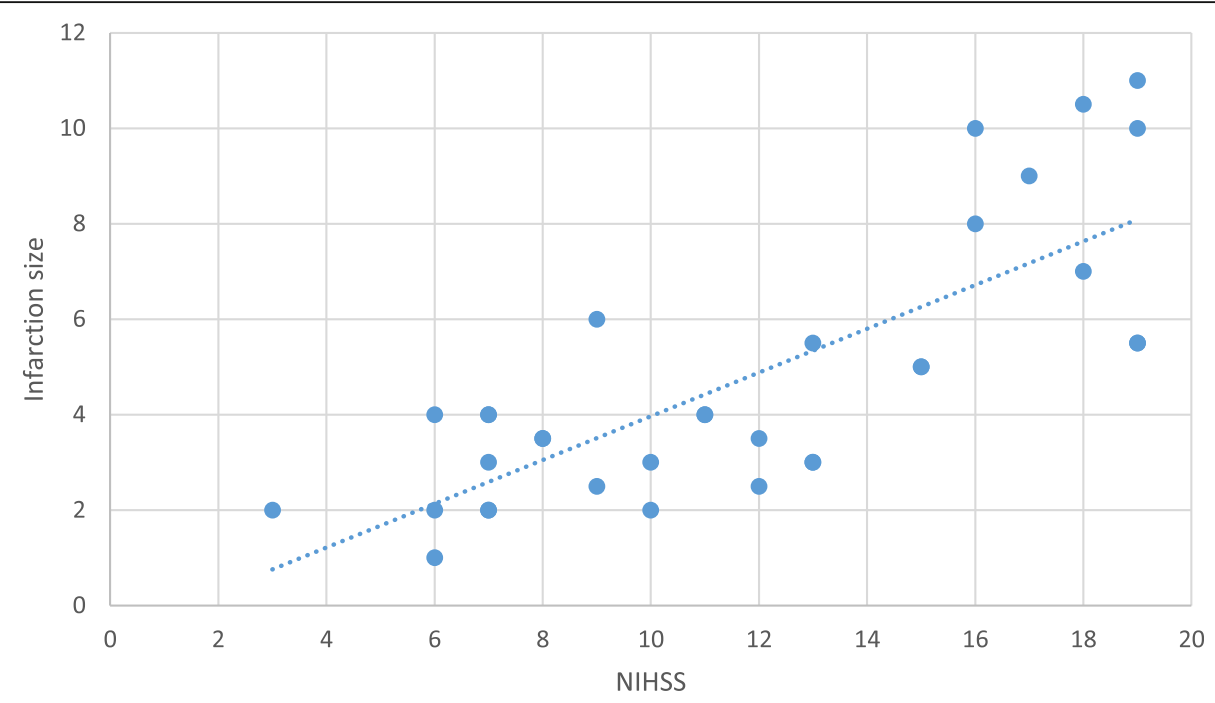

Fig. 1 Correlation between NIHSS score on admission and infarction size

necrotic cerebral tissue followed by activation of the microglia and alteration of blood-brain barrier permeability. Subsequent leukocytic rolling on activated endothelium, recruitment (E-selectin effect), and transendothelial migration (VCAM-1 effect) into the brain parenchyma lead to infiltration of brain tissue with macrophages, granulocytes, and $\mathrm{T}$ cells. Leukocyte aggregation and adhesion to vascular wall result in expansion of the infarction from the penumbra and further clinical deterioration [7, 37]. Furthermore, higher hs-CRP levels were correlated with larger infarct volumes in AIS in the study of Youn and colleagues [38].

E-selectin, VCAM-1, and hs-CRP were positively correlated with follow-up mRS. Nevertheless, their baseline levels were not significantly different between the groups of good and poor outcomes, and subsequently, they could not be useful as prognostic biomarkers of short-term stroke outcome. Although Kanai and colleagues [39] suggested that serum hs-CRP level was useful as a predictor of future cerebral infarction in type 2 diabetic patients, they doubted its ability to indicate functional outcome. Inconsistent with our finding, Di Napoli and colleagues [40] found that CRP was an independent prognostic factor in stroke. In another study, VCAM-1 levels greater than $208 \mathrm{pg} / \mathrm{ml}$ were independently associated with the presence of early neurological deterioration and poor outcome at 3 months [41].

The trend of both VCAM-1 and E-selectin was to decrement in patients who exhibited favorable short-term outcome and increment in patients who exhibited poor outcome. But considering the statistical significance, we could conclude that significant increase in the level of serum VCAM-1 but not E-selectin was linked to poor clinical short-term outcome, while significant decrease in the level of serum E-selectin but not VCAM-1 was linked to clinical improvement. E-selectin is the first to be released by activated endothelial cells during the first $24 \mathrm{~h}$ with rapid decrease. High levels of VCAM-1 are found later in the blood and remain for several days. Brain ischemia-induced inflammatory responses exhibit both acute and chronic phases. While acute inflammatory events are detrimental and propagating tissue damage, more delayed inflammatory events are beneficial

Table 7 Correlation between INHSS score, infarction size, and levels of laboratory markers on admission

\begin{tabular}{|c|c|c|c|c|}
\hline \multirow{2}{*}{$\begin{array}{l}\text { Laboratory } \\
\text { marker }\end{array}$} & \multicolumn{2}{|l|}{$\mathrm{NIHSS}$} & \multicolumn{2}{|l|}{ Infarction size } \\
\hline & Correlation coefficient $(r)$ & $P$ value & Correlation coefficient $(r)$ & $P$ value \\
\hline E-selectin (ng/ml) & 0.42 & $0.047^{*}$ & 0.54 & $0.03^{*}$ \\
\hline VCAM-1 (ng/ml) & 0.44 & $0.009^{* *}$ & 0.45 & $0.02^{*}$ \\
\hline hs-CRP (mg/l) & 0.52 & $0.002^{* *}$ & 0.46 & $0.04^{*}$ \\
\hline Prolactin (ng/ml) & 0.45 & $0.008^{* *}$ & 0.53 & $0.03^{*}$ \\
\hline MPV (fl) & 0.50 & $0.003^{* *}$ & 0.49 & $0.02^{*}$ \\
\hline
\end{tabular}

NIHSS National Institute of Health Stroke Scale, VCAM-1 vascular cell adhesion molecule 1, hs-CRP high sensitivity C-reactive protein, MPV mean platelet volume ${ }^{*} P$ value $<0.05$ is significant

**P value $<0.01$ is highly significant 


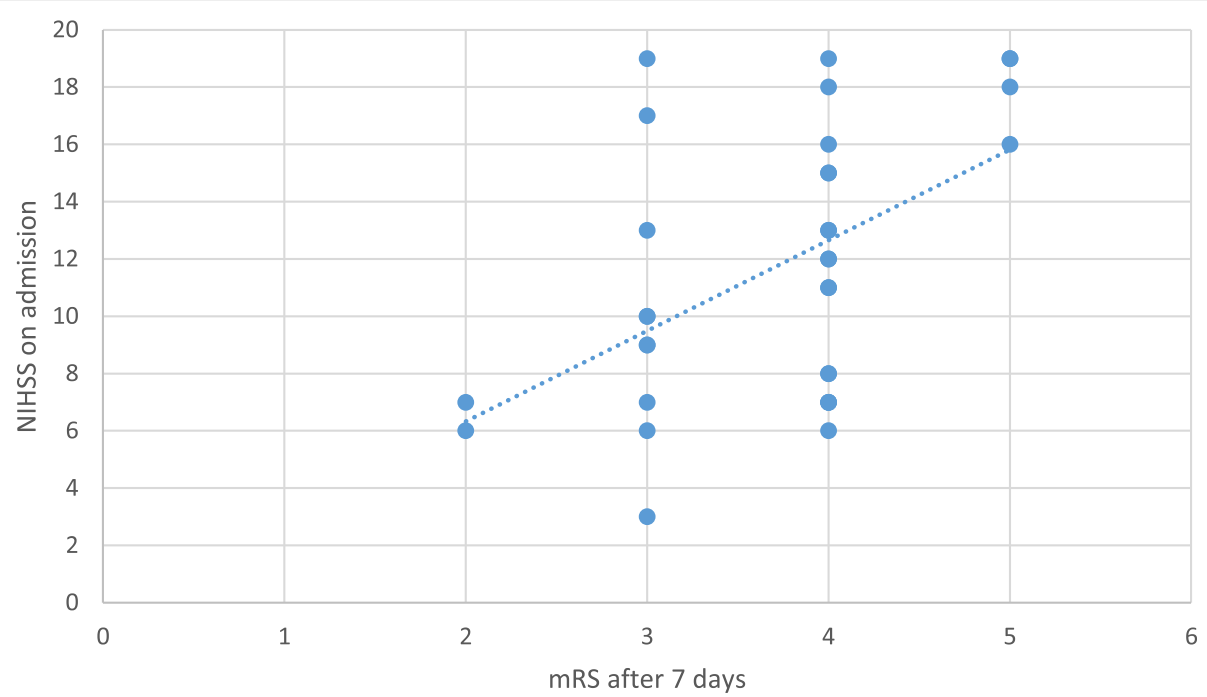

Fig. 2 Correlation between modified Rankin scale (mRS) after 7 days and National Institute of Health Stroke Scale (NIHSS) score on admission

and permit clearance of necrotic debris and tissue repair $[2,37]$. In accordance with our results, high levels of Eselectin and VCAM-1 at stroke onset have been described to decrease in patients who experienced clinical improvement and have shown no change in those who did not improve [36].

\section{Prolactin}

In our study, levels of PRL were increased in stroke patients at the onset in comparison to matched healthy controls. This finding was consistent with that of Tripathi and colleagues [42]. Regarding the role played by prolactin in acute cerebral infarction, one could not separate between its immune- modulatory and thrombogenic effects. As a cytokine, PRL influences proliferation, regulation, and communication of inflammatory cells [4]. Furthermore, it leads to platelet activation and arterial thrombogenesis through direct enhancement of ADP and P-selectin expression [5]. On the other hand, Schwarz and colleagues [43] attributed this phenomenon to hypothalamic-pituitary-adrenocortical axis disturbances in response to stress through alterations in the dopaminergic pathways. However, more studies are needed to clarify whether this increase is a primary or secondary phenomenon. In the present study, there was a positive correlation between initial stroke severity (NIHSS score and infarction size) and levels of PRL at disease onset. This further

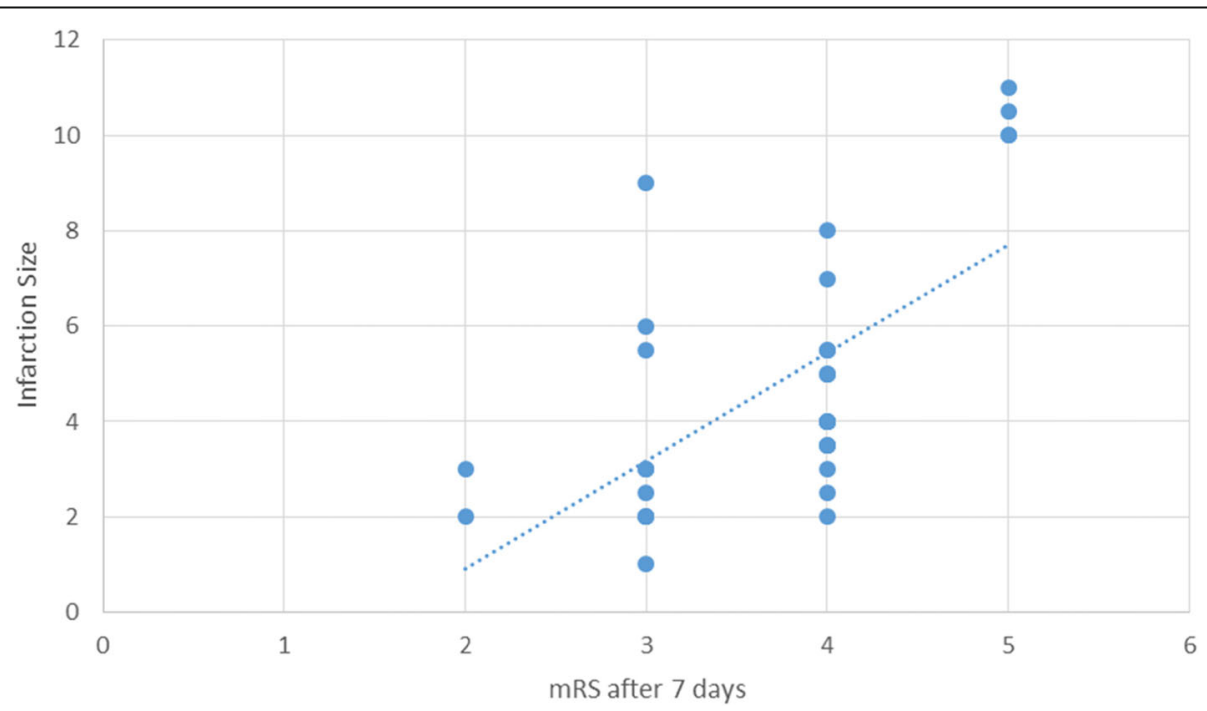

Fig. 3 Correlation between modified Rankin scale (mRS) after 7 days and infarction size 
Table 8 Correlation between stroke outcome (measured by $\mathrm{mRS}$ ) and laboratory markers on admission

\begin{tabular}{lll}
\hline \multirow{2}{*}{$\begin{array}{lll}\text { Laboratory } \\
\text { marker }\end{array}$} & mRS after 7 days (stroke outcome) \\
\cline { 2 - 3 } E-selectin $(\mathrm{ng} / \mathrm{ml})$ & 0.38 & $P$ value \\
\hline VCAM-1 $(\mathrm{ng} / \mathrm{ml})$ & 0.37 & $0.02^{*}$ \\
hs-CRP $(\mathrm{mg} / \mathrm{l})$ & 0.36 & $0.03^{*}$ \\
Prolactin $(\mathrm{ng} / \mathrm{ml})$ & 0.37 & $0.03^{*}$ \\
MPV (fl) & 0.57 & $0.03^{*}$ \\
\hline
\end{tabular}

mRS modified Rankin score, VCAM-1 vascular cell adhesion molecule 1, hs-CRP high sensitivity C-reactive protein, MPV mean platelet volume

${ }^{*} P$ value $<0.05$ is significant

supports the hypothesis that PRL contributes to stroke pathogenesis and progression. In our study, there was a statistically significant correlation between PRL and mRS at follow-up; however, its baseline levels did not show significant differences between the group of good and that of poor short-term outcome. Previously, Bhatia and colleagues [44] concluded that prolactin and platelet aggregation did not affect stroke outcome and did not show any significant difference amongst expired patients and survivors. In contrast, poor prognosis was correlated with increased prolactin and consequently platelet aggregability [45].

\section{Mean platelet volume}

MPV is a marker for platelet activation and thrombogenesis that occur in initial phases of ischemic stroke. Larger-sized platelets are more reactive, and their activation is mediated via inflammatory mediators especially prolactin [5]. Hence, in our study, the significant increase in MPV in patient group compared with the control group and its positive correlation with stroke severity (NIHSS on admission and infarction size) were expected. In an attempt to explain the increase in platelets volume, Jackson and colleagues [45] suggested the emergence of young large platelets in peripheral circulation as a consequence to reduction in their numbers during the first $48 \mathrm{~h}$ of stroke due to their retention in the infarct areas. Currently, there are conflicting discussion regarding the risk and prognostic impact of MPV in patients with cerebral infarction. The first question is whether MPV elevation emerges prior to or following the stroke, and the second is whether persistent MPV elevation can predict future ischemic events and subsequently serve as an objective long-term prognostic element. Greisenegger and colleagues [46] noted that higher MPV values led to increase in the risk of stroke. The short follow-up period in the present study precluded a conclusion regarding this issue; however, we could conclude that MPV did not differ significantly between the group of good and that of poor outcome and was not a suitable predictor of short-term outcome. In agreement with the current results, earlier studies doubted any relationship between early ischemic stroke and MPV [8] or between platelet behavior and prognosis after 6 months [47]. On contrary, another study showed that on admission, MPV elevation was associated with poor clinical outcome independently of concomitant factors [46]. One explanation of this controversy is the differences in the follow-up periods in various studies. Elevated MPV may persist for 1 month after the acute event, a finding that could explain the insignificant change in the follow-up readings of this parameter in both outcome groups [5].

\section{Limitations}

Although we tried to minimize the effect of comorbidity on the inflammatory markers by excluding patients with increased carotid IMT, other medical conditions that might be associated with alteration in the inflammatory markers or MPV such as stroke complications [48], analgesic use, systemic lupus erythematosus [49], antiphospholipid syndrome, or earlier onset ischemic heart disease [50] could not be totally avoided. Moreover, small sample size and possible referral bias (because the study was carried out in a tertiary center) are considered as weak points and limited the generalizability of the results. In addition, transesophageal echo should be done since the most frequently encountered risk factors were cardiac diseases. It was "scheduled," but results were not available by the time of assessment "during the first week after acute event."

\section{Conclusion}

Higher NIHSS score at disease onset and large infarction size are independent indicators of unfavorable short-term outcome. Baseline elevations of cell adhesion molecules, hs-CRP, PRL, and MPV and their significant correlation with stroke severity denote that they may contribute to stroke pathophysiology and progression. Levels of inflammatory markers and MPV at stroke onset could not predict short-term outcome, although E-selectin and VCAM1 trends to increment or decrement within the first few days of hospitalization may serve this issue.

\section{Acknowledgements \\ The authors thank the members of Kasr Alainy Stroke Unit for their help in data collection.}

\section{Authors' contributions}

All authors contributed to the study. AD was the main investigator. AE, Al, and MF helped in the patient recruitment and assessment. LR helped in the laboratory work. All authors read and approved the final manuscript.

\section{Funding}

This research did not receive any specific grant from funding agencies in the public, commercial, or not-for-profit sectors.

\section{Availability of data and materials}

The datasets used and/or analyzed during the current study are available from the corresponding author on reasonable request. 


\section{Ethics approval and consent to participate}

Informed consents were obtained from the participants or their relatives. The ethical committee of Neurology Department, Cairo University, approved the study on 20 September 2016.

\section{Consent for publication}

Not applicable.

\section{Competing interests}

The authors declare that they have no competing interests.

\section{Received: 9 May 2019 Accepted: 10 October 2019}

Published online: 02 December 2019

\section{References}

1. Béjot Y, Daubail B, Jacquin A, Durier J, Osseby GV, Rouaud O, et al. Trends in the incidence of ischaemic stroke in young adults between 1985 and 2011: the Dijon Stroke Registry. J Neurol Neurosurg Psychiatry. 2014;85:509-13.

2. Bethea JR, Dietrich WD. Targeting the host inflammatory response in traumatic spinal cord injury. Curr Opin Neurol. 2002;15:355-60.

3. Harvey S, Aramburo C, Sanders EJ. Extrapituitary production of anterior pituitary hormones: an overview. Endocrine. 2012:41:19-30.

4. Tang MW, Garcia S, Gerlag DM, Tak PP, Reedquist KA. Insight into the endocrine system and the immune system: a review of the inflammatory role of prolactin in rheumatoid arthritis and psoriatic arthritis. Front Immunol. 2017:8:720.

5. Wallaschofski H, Stumpf C, Raaz D, Yilmaz A, Cicha I, Klinghammer L, et al. Increased prolactin in acute coronary syndromes as putative Co-activator of ADP-stimulated P-selectin expression. Horm Metab Res. 2006;38(11):767-72.

6. Bath P, Algert C, Chapman N, Neal B. Association of mean platelet volume with risk of stroke among 3134 individuals with history of cerebrovascular disease. PROGRESS Collaborative Group. Stroke. 2004;35(3):622-6.

7. Richard S, Lagerstedt L, Burkhard PR, Debouverie M, Turck N, Sanchez J-C. Eselectin and vascular cell adhesion molecule-1 as biomarkers of 3-month outcome in cerebrovascular diseases. J Inflamm (Lond). 2015;12:61.

8. Sacco RL, Adams R, Albers G, Alberts MJ, Benavente O, Furie K, et al. Guidelines for prevention of stroke in patients with ischemic stroke or transient ischemic attack: a statement for healthcare professionals from the American Heart Association/American Stroke Association Council on Stroke: co-sponsored by the Council on Cardiovascular Radiology and Intervention. Stroke. 2006;37(2):577-617.

9. Adams HP Jr, Bendixen BH, Kappelle LJ, Biller J, Love BB, Gordon DL, et al. Classification of subtype of acute ischemic stroke. Definitions for use in a multicenter clinical trial. TOAST. Trial of Org 10172 in Acute Stroke Treatment. Stroke. 1993;24:35-41.

10. Pan SL, Wu SC, Wu TH, Lee TK, Chen TH. Location and size of infarct on functional outcome of noncardioembolic ischemic stroke. Disabil Rehabil. 2006;28(16):977-83.

11. Zeng X, Zhang G, Yang B, Zhang B, Zhang L, Ni Y, et al. Neopterin as a predictor of functional outcome and mortality in Chinese patients with acute ischemic stroke. Mol Neurobiol. 2016;53(6):3939-47.

12. Adams HP Jr, Kappelle LJ, Biller J, Gordon DL, Love BB, Gomez F, et al. Ischemic stroke in young adults. Experience in 329 patients enrolled in the lowa Registry of stroke in young adults. Arch Neurol. 1995;52:491-5.

13. Kittner SJ, Stern BJ, Wozniak M, Buchholz DW, Earley CJ, Feeser BR, et al. Cerebral infarction in young adults: the Baltimore-Washington Cooperative Young Stroke Study. Neurology. 1998;50:890-4.

14. Leys D, Bandu L, Hénon H, Lucas C, Mounier-Vehier F, Rondepierre P, et al. Clinical outcome in consecutive young adults (15 to 45 years) with ischemic stroke. Neurology. 2002;59:26-33.

15. Naess H, Nyland HI, Thomassen L, Aarseth J, Myhr KM. Etiology of and risk factors for cerebral infarction in young adults in western Norway: a population based case-control study. Eur J Neurol. 2004;11:25-30.

16. Corso G, Bottacchi E, Tosi P, Caligiana L, Lia C, Morosini MV, et al. Outcome predictors in first-ever ischemic stroke patients: a population based study. Int Sch Res Notices. 2014:8.

17. Fusco M, Harrigan M. Cerebrovascular dissections-a review part I: spontaneous dissections. Neurosurgery. 2011;68:242-57.

18. Kristensen B, Malm J, Carlberg B, Stegmayr B, Backman C, Fagerlund M, et al. Epidemiology and etiology of ischemic stroke in young adults aged 18 to 44 years in northern Sweden. Stroke. 1997;28:1702-9.
19. Putaala J, Yesilot N, Waje-Andreassen U, Pitkäniemi J, Vassilopoulou S, Nardi $K$, et al. Demographic and geographic vascular risk factor differences in European young adults with ischemic stroke: the 15 cities young stroke study. Stroke. 2012;43:2624-30

20. Rutten-Jacobs L, Maaijwee NA, Arntz RM, Schoonderwaldt HC, Dorresteijn LD, van der Vlugt MJ, et al. Long-term risk of recurrent vascular events after young stroke: the FUTURE study. Ann Neurol. 2013;74:592-601.

21. Sorour K. A Rheumatic heart disease in Egypt, gloomy past and promising future. Egypt Heart J. 2014;66(2):139-42.

22. Saposnik G, Cote R, Phillips S, Gubitz G, Bayer N, Minuk J. Stroke outcome in those over 80. a multicenter cohort study across Canada. Stroke. 2008;9: 2310 .

23. Shobha N, Sylaja PN, Kapral MK, Fang J, Hill MD. Differences in stroke outcome based on sex. Investigators of the Registry of the Canadian Stroke Network. Neurology. 2010;74(9):767-71.

24. Thijs VN, Lansberg MG, Beaulieu C, Marks MP, Moseley ME, Albers GW. Is early ischemic lesion volume on diffusion-weighted imaging an independent predictor of stroke outcome? A multivariable analysis. Stroke. 2000;31:2597-602

25. Johnston KC, Connors AF Jr, Wagner DP, Knaus WA, Wang X, Haley EC Jr. A predictive risk model for outcomes of ischemic stroke. Stroke. 2000;31:448-55

26. Wardlaw JM, Dorman PJ, Candelise L, Signorini DF, on behalf of the MASTItaly Collaborative Group. The influence of baseline prognostic variables on outcome after thrombolysis. J Neurol. 1999;246:1059-62.

27. Haeusler KG, Gerischer LM, Vatankhah B, Audebert HJ, Nolte CH. Impact of hospital admission during nonworking hours on patient outcomes after thrombolysis for stroke. Stroke. 2011;42:2521-5.

28. Zhou X, Yu F, Feng X, Wang J, Li Z, Zhan Q, et al. Immunity and inflammation predictors for short-term outcome of stroke in young adults. Int J Neurosci. 2018;128(7):634-9.

29. Boone M, Chillon JM, Garcia PY, Canaple S, Lamy C, Godefroy O, et al. NIHSS and acute complications after anterior and posterior circulation strokes. Ther Clin Risk Manag. 2012;8:87-93.

30. Brott T, Marler JR, Olinger CP, Adams HP Jr, Tomsick T, Barsan WG, et al. Measurements of acute cerebral infarction: lesion size by computed tomography. Stroke. 1989;20:871-5.

31. Chen C-L, Tang F-T, Chen H-C, Chung C-Y, Wong M-K. Brain lesion size and location: effects on motor recovery and functional outcome in stroke patients. Arch Phys Med Rehabil. 2000;81:447-52.

32. Beloosesky JY, Streifler A, Burstin J. The importance of brain infarct size and location in predicting outcome after stroke. Age Ageing. 1995;18:183-91.

33. Wang J, Gao L, Yang Y-L, Li Y-Q, Chang T, Man M-H, et al. Low serum levels of brain-derived neurotrophic factor were associated with poor shortterm functional outcome and mortality in acute ischemic stroke. Mol Neurobiol. 2017:54:7335-42.

34. Tsai NW, Chang WN, Shaw CF, Huang CR, Chen SD, Chuang YC, et al. The value of leukocyte adhesion molecules in patients after ischemic stroke. J Neurol. 2009;256:1296-302.

35. Petruzzelli $L$, Takami M, Humes HD. Structure and function of cell adhesion molecules. Am J Med. 1999;106(4):467-76.

36. Blum A, Khazim K, Merei M, Peleg A, Blum N, Vaispapir V. The stroke trialcan predict clinical outcome of patients with ischemic stroke by measuring soluble cell adhesion molecules (CAM)? Eur Cytokine Netw. 2006;17:295-8.

37. O'Carroll SJ, Kho DT, Wiltshire R, Nelson V, Rotimi O, Johnson R, et al. Proinflammatory TNFa and IL-1 $\beta$ differentially regulate the inflammatory phenotype of brain microvascular endothelial cells. J Neuroinflammation. 2015;12:131.

38. Youn CS, Choi SP, Kim SH, Oh SH, Jeong WJ, Kim HJ, et al. Serum highly selective C-reactive protein concentration is associated with the volume of ischemic tissue in acute ischemic stroke. Am J Emerg Med. 2012;30:124-8.

39. Kanai A, Kawamura T, Umemura T, Nagashima M, Nakamura N, Nakayama $M$, et al. Association between future events of brain infarction and soluble levels of intercellular adhesion molecule- 1 and $C$ reactive protein in patients with type 2 diabetes mellitus. Diabetes Res Clin Pract. 2008;82:157-64.

40. Di Napoli M, Papa F, Bocola V. C-reactive protein in ischemic stroke: an independent prognostic factor. Stroke. 2001;32:917-24.

41. DeGraba TJ. The role of inflammation after acute stroke. Utility of pursuing antiadhesion molecule therapy. Neurology. 1998;51(3):S62-8.

42. Tripathi SK, Kamble P, Muddeshwar MG. Serum prolactin level in patients of ischemic stroke. Int J Contemp Med Res. 2016;3(12):3459-60. 
43. Schwarz S, Schwab S, Klinga K, Maser-Gluth C, Bettendorf M. Neuroendocrine changes in patients with acute space occupying ischaemic stroke. J Neurol Neurosurg Psychiatry. 2003;74(6):725-7.

44. Bhatia RS, Garg RK, Gaur SP, Kar AM, Shukla R, Agarwal A, et al. Predictive value of routine hematological and biochemical parameters on 30-day fatality in acute stroke. Neurology. 2004;52(2):127-56.

45. Jackson SR, Carter JM. Platelet volume: laboratory measurement and clinical application. Blood Rev. 2013;7(2):104-13.

46. Greisenegger S, Endler G, Hsieh K, Tentschert S, Mannhalter C, Lalouschek $W$. Is elevated mean platelet volume associated with a worse outcome in patients with acute ischemic cerebrovascular events? Stroke. 2004;35(7): 1688-91.

47. O'Malley T, Langhorne P, Elton RA, Stewart C. Platelet size in stroke patients. Stroke. 1995;26(6):995-9.

48. Rodríquez-Yáñez M, Castellanos M, Blanco M, García MM, Nombela F, Serena J, et al. New-onset hypertension and inflammatory response/poor outcome in acute ischemic stroke. Neurology. 2006;67:1973-8.

49. Ikeda Y, Fujimoto T, Ameno M, Shiiki H, Dohi K. Relationship between lupus nephritis activity and the serum level of soluble VCAM-1. Lupus. 1998;7:347-54

50. Zeitler H, Ko Y, Zimmermann C, Nickenig G, Glänzer K, Walger P, et al. Elevated serum concentrations of soluble adhesion molecules in coronary artery disease and acute myocardial infarction. Eur J Med Res. 1997;2(9):389-94.

\section{Publisher's Note}

Springer Nature remains neutral with regard to jurisdictional claims in published maps and institutional affiliations.

\section{Submit your manuscript to a SpringerOpen ${ }^{\circ}$ journal and benefit from:}

- Convenient online submission

- Rigorous peer review

- Open access: articles freely available online

- High visibility within the field

- Retaining the copyright to your article 